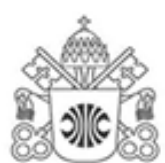 \\ PUC Minas

\section{Atributos e Valores para o Desenvolvimento de Jogos para Idosos*}

Attributes and Values for the Development of Games for the Elderly

\author{
Artur Martins $\mathrm{Mol}^{1}$ \\ Hebert Phillipe Martins Pereira ${ }^{2}$ \\ Ana Luiza do Nascimento Guercy ${ }^{3}$ \\ Michelle Nery Nascimento ${ }^{4}$ \\ Mônica da Consolação Machado ${ }^{5}$ \\ Lucila Ishitani ${ }^{6}$
}

\begin{abstract}
Resumo
Com o aumento da expectativa de vida, o envelhecimento saudável passou a ser uma necessidade do meio social. Jogos digitais têm o potencial de melhorar o tempo de lazer e a conexão social dos idosos, além de ser uma opção de ferramenta que pode beneficiar a função cognitiva. No entanto, a maioria dos jogos digitais atualmente disponíveis no mercado são direcionados ao público mais jovem, e contêm conteúdo que, geralmente, não são atrativos para os idosos. Visando identificar os atributos e valores em jogos que sejam interessantes na perspectiva dos idosos, foi aplicada a teoria meios-fins. Para isso, foram realizadas entrevistas com 22 participantes com idade a partir de 60 anos, utilizando a técnica de laddering, que permite gerar, como um de seus resultados, o Mapa Hierárquico de Valor. As hierarquias construídas permitiram o entendimento das relações entre os atributos dos jogos, as consequências e os valores relatados sob o ponto de vista dos idosos entrevistados. Os 16 atributos identificados, em conjunto com as 12 consequências e 12 valores contribuem para o desenvolvimento de jogos com foco no público da terceira idade.
\end{abstract}

Palavras-chave: Jogos digitais. Idosos. Teoria meios-fins. Valores.

\footnotetext{
*Submetido em 27/09/2020 - Aceito em 17/09/2021

${ }^{1}$ Programa de Pós-graduação em Informática da PUC Minas, Brasil- amol@ pucminas.br

${ }^{2}$ Programa de Pós-graduação em Informática da PUC Minas, Brasil- hebert.pereira.dev@gmail.com

${ }^{3}$ Programa de Pós-graduação em Informática da PUC Minas, Brasil-analuizanascimento95@ @otmail.com

${ }^{4}$ Programa de Pós-graduação em Informática da PUC Minas, Brasil- micnery@gmail.com

${ }^{5}$ Programa de Pós-graduação em Informática da PUC Minas, Brasil-monicacmachado@ hotmail.com

${ }^{6}$ Programa de Pós-graduação em Informática da PUC Minas, Brasil- lucila@ pucminas.br
} 


\begin{abstract}
With the increase of life expectancy, a healthy aging turned to be an important topic for the society. Digital games have the potential to improve leisure time and social connection of older people, besides being an option that can benefit cognitive functions. However, most of the digital games currently available on the market are aimed at the young people and have content and characteristics that are generally unattractive to older people. In order to identify the attributes and values in games that are interesting from the perspective of the older people, the means-end theory was applied. For this purpose, interviews were conducted with 22 participants aged 60 and over, using the laddering technique, which allows to generate, as one of its results, a Hierarchical Value Map (HVM). The HVM built allowed the understanding of the relations among the attributes, consequences and values reported by the participants. The 16 attributes identified, together with the 12 consequences and 12 values contribute to the development of games with a focus on older people.
\end{abstract}

Keywords: Digital games. Older people. Means-end theory. Values. 


\section{INTRODUÇÃO}

De acordo com a Organização das Nações Unidas (ONU, 2019), o número de idosos no mundo está aumentando e será de cerca de 2 bilhões em 2050. Esse número significativo de pessoas merece atenção, pois com o envelhecimento, várias habilidades cognitivas e motoras começam a declinar, e esses declínios relacionados à idade podem dificultar a realização de atividades diárias. Portanto, uma questão de crescente importância é como ajudar os idosos a manter habilidades que sustentam o desempenho das atividades diárias da vida.

Gerling, Schild e Masuch (2010) argumentam que os jogos digitais podem ajudar a diminuir os efeitos negativos do envelhecimento. Jogos proporcionam aos idosos entretenimento, relaxamento, desafios mentais, sintomas reduzidos de depressão, aumento das interações sociais e uma opção para aprender novas atividades (MACHADO, 2014; RICE et al., 2011; IJSSELSTEIJN et al., 2007). Além disso, jogos podem estimular o raciocínio e o questionamento sobre assuntos que passariam despercebidos, mudando e até mesmo ajudando a formar opiniões sobre diferentes tópicos. Ao se envolver com jogos, as pessoas podem se deparar com questões presentes em suas vidas diárias, como violência, religião, questões raciais e éticas (FLANAGAN, 2016). Diante desses benefícios, torna-se importante desenvolver jogos que atendam aos interesses dos idosos.

Este artigo tem como objetivo apresentar uma lista de atributos em jogos que mais agradam ao público idoso na perspectiva dos mesmos. Para atingir esse objetivo, foi realizado um estudo exploratório. Os dados foram coletados por meio de entrevistas utilizando uma técnica de entrevistas denominada laddering.

Para descobrir os atributos implícitos dos jogos, na perspectiva dos idosos entrevistados, e identificar as consequências e os valores correspondentes, foi aplicada a Teoria da Cadeia de Meios-Fins. Essa teoria está enraizada em uma abordagem cognitiva e implica que o significado subjetivo de um produto seja estabelecido por associações entre seus atributos e categorias cognitivas mais abstratas e centrais, como valores, que podem motivar o comportamento e criar interesse nos atributos do produto. A teoria das cadeias de meios-fins sustenta que a maneira como os consumidores se relacionam com os produtos pode ser representada por um modelo hierárquico de três níveis interconectados: atributos do produto, consequências do uso e valores. O resultado é um conjunto de cadeias de valor que vinculam cada atributo de produto às suas consequências, que podem ser funcionais ou psicossociais (emocionais), e essas a valores pessoais subjacentes.

No total, foram identificados 16 atributos, 12 consequências e 12 valores que contribuem para o desenvolvimento de jogos com foco no público da terceira idade. Dentre os valores, encontra-se a Realização pessoal; dentre as consequências, a preocupação com a saúde mental; e, por fim, dentre os atributos, jogos que oferecem desafios, que exigem raciocínio e agilidade.

O artigo está estruturado da seguinte forma: a Seção 2 apresenta conceitos básicos para a compreensão deste trabalho; a Seção 3 detalha a metodologia adotada; a Seção 4 apresenta os principais resultados obtidos e, em seguida, a Seção 5 discute esses resultados. Por fim, a 
Seção 6 apresenta as conclusões deste trabalho e sugestões de trabalhos futuros.

\section{FUNDAMENTAÇÃO TEÓRICA}

Nesta seção é apresentada a fundamentação teórica deste trabalho. São apresentados os conceitos de valores, design sensível a valor e teoria meios-fins.

\subsection{Valores}

Schwartz e Bilsky (1987) definem valores como "conceitos ou crenças, sobre estados ou comportamentos finais desejáveis, que transcendem situações específicas, orientam a seleção ou avaliação de comportamentos e eventos e são ordenados por importância relativa". Rokeach (1973) complementa dizendo que eles são "uma crença duradoura e centralizada que guia ações e julgamentos em situações específicas, e além de metas imediatas, para os estados finais de existência mais avançados". Rokeach (1973) argumenta ainda que os valores podem ser relativos a uma situação. Por exemplo, o valor "não agredir", embora na maioria dos casos seja considerado positivo, quando colocado em um contexto de autodefesa ou proteção de entes queridos, pode ser justificável ir contra esse valor. Além disso, um indivíduo pode ter valores que conflitam entre si, mas isso não significa que alguns sejam necessariamente verdadeiros e outros, falsos (BERLIN, 2013).

De acordo com Flanagan (2016), os valores podem ser divididos em várias categorias, tais como: ambiental (diversidade de espécies, proteção de rios, preservação de florestas), pessoal (sinceridade, honestidade, caridade), político (justiça, democracia, social), inacessível (paz mundial, igualdade, tolerância). Na literatura, há tentativas de encontrar valores que possam ser considerados universais, presentes em diferentes culturas.

No campo da psicologia social, Rokeach (1973) criou uma lista de classificação de valores conhecida como Rokeach Value Survey (RVS). O RVS é composto por 36 valores organizados em duas categorias: 18 valores terminais e 18 valores instrumentais. Valores terminais são valores que um indivíduo deseja alcançar ao longo da vida, e valores instrumentais são formas de se comportar ou meios de atingir valores terminais. Em seu trabalho, Rokeach afirma que sua lista foi obtida por meio de entrevistas com uma amostra de cerca de 100 adultos. No entanto, existem críticas a seu trabalho, focadas principalmente na metodologia adotada para chegar aos 36 valores levantados e se esses valores são realmente universais (JONES; SENSENIG; ASHMORE, 1978; GIBBINS; WALKER, 1993). 


\subsection{Design sensível a valor}

Os sistemas interativos são uma realidade crescente em todo o mundo, e as pessoas os utilizam para diversos fins, por meio de vários dispositivos e em contextos bastante diferentes e complexos. Existem diversos exemplos positivos e negativos do que a tecnologia interativa causa em um ambiente social: da exposição a questões de segurança da informação e da exclusão digital à autonomia do usuário na operação de sistemas.

Conforme descrito por Pereira e Baranauskas (2015), a maneira como a tecnologia é projetada influenciará o comportamento dos indivíduos e o contexto cultural em que está sendo usada. Por outro lado, sabe-se que valores, culturas e crenças mudam a maneira como a tecnologia é entendida e usada, bem como o impacto que ela pode ter no meio ambiente e nas pessoas. Embora exista literatura dedicada ao tema dos valores, Pereira e Baranauskas (2015) aponta para a falta de artefatos, métodos e princípios para apoiar pesquisadores e profissionais em suas atividades de identificação e agregação de valor à tecnologia.

De acordo com Pereira e Baranauskas (2015), a evidência das implicações de valores (ou falta de) é frequentemente muito sutil e só é percebida quando uma regra social é violada, um padrão de comportamento é quebrado ou surge um conflito de interesses. Eles também afirmam que a análise de valor em tecnologia geralmente ocorre após o design e o lançamento do produto, e a presença de valores só é gerenciada quando eles se destacam, positiva ou negativamente.

Essa indiferença à identificação de valores no contexto do desenvolvimento de programas e produtos ressalta a necessidade de investigar e entender como os valores são promovidos ou inibidos pelas tecnologias. De acordo com Bannon (2011), as reais necessidades, preocupações e valores das pessoas envolvidas são secundárias. Pensar no desenvolvimento tecnológico ou na assistência à saúde antes de entender as diferenças envolvidas e seus valores pode dificultar a compreensão de questões mais básicas, como a necessidade de as pessoas entrarem em contato com a família, amigos e vizinhos de uma maneira natural e a necessidade de gerenciar sua privacidade e autonomia.

O design sensível a valor concentra-se em extrair os valores mais importantes que uma pessoa tem na vida e em atingir esses valores. Dessa forma, o design sensível a valor pode ser considerado uma extensão do design centrado no usuário. O design centrado no usuário é basicamente "centrado em artefato" e é focado na identificação dos recursos do produto que os usuários desejam. Por sua vez, o design sensível a valor visa criar um design amigável que atenda aos valores de uma pessoa na vida, e os valores podem ser entendidos como os ideais ou os interesses do usuário. Por exemplo, um valor para um idoso pode ser sua vida familiar e, consequentemente, suas ações na vida serão motivadas por esse valor. De acordo com Boerema et al. (2017), o design sensível a valor pode ser considerado uma maneira pela qual os valores dos usuários e os fatores que os motivam a usar um produto específico são elicitados, analisados e mapeados em um processo de design centrado no usuário. Um novo foco em valor ou valores muda a atenção do contexto de uso para o contexto de impacto. 


\subsection{Teoria meios-fins}

A teoria meios-fins (do inglês means-end theory) refere-se a um conjunto de métodos para se entrevistar consumidores sobre os motivos que os levaram a uma determinada escolha/decisão e interpretar essas respostas na forma de uma cadeia de resultados conectados (REYNOLDS; OLSON, 2001). Segundo Gutman (1982), a teoria meios-fins é baseada em algumas suposições sobre o comportamento humano:

1. valores, ou estados finais desejáveis, desempenham um papel dominante na orientação de padrões de escolha;

2. pessoas lidam com a diversidade de produtos que são capazes de satisfazer seus valores agrupando-os em conjuntos ou classes, com o objetivo de reduzir a complexidade da escolha;

3. todas as ações humanas possuem consequências;

4. as pessoas associam determinadas consequências a ações específicas.

Em outras palavras, a teoria meios-fins pressupõe que as pessoas decidem quais produtos e serviços adquirir com base nas consequências previstas (resultados experimentados, satisfação de necessidades, meta ou realização de valor) associadas a cada alternativa considerada. Normalmente, essas consequências derivam das ações envolvidas no uso dos produtos e serviços em questão.

Olson e Peter (2008) explicam que as pessoas possuem três níveis de conhecimento relacionados a um produto: atributos do produto, consequências do uso de um produto e os valores (ou objetivos) que podem ser alcançados pelo uso desse produto. Segundo Botschen (1999), cada nível pode se dividir em dois sub-níveis como observado na Figura 1. Os atributos são características que podem ser preferidas ou procuradas pelo consumidor. Esses atributos podem ter dois níveis: os concretos são características quantificáveis e mensuráveis do produto, como possuir um ranking ou possuir animações; e os abstratos são atributos percebidos, mas não mensuráveis, tais como ser divertido ou ser bonito. As consequências são resultados da presença desses atributos. Elas podem ser divididas em funcionais ou psicossociais. As funcionais são diretas, como a percepção do consumidor de que está melhorando em algum aspecto, que está sentindo prazer. Já as psicossociais são consequências de nível mais alto, que podem envolver questões emocionais e afetivas, bem como os benefícios sociais provenientes dessas percepções, as que o consumidor irá usar em outras atividades sociais como raciocinar melhor para vencer desafios na vida, aprender, se distrair. Já os valores são definidos por Rokeach (1973) como multifacetados e funcionam como um guia condutor em diversos aspectos. Os valores instrumentais estão relacionados ao comportamento. É a motivação, pois são os comportamentos idealizados, instrumentos, para se obter os estados finais desejados. Como exemplo, pode-se citar: sentir-se capaz é um caminho para se ter autoestima. O interesse em aprender o 


\section{Figura 1 - Representação de uma cadeia meios-fim}

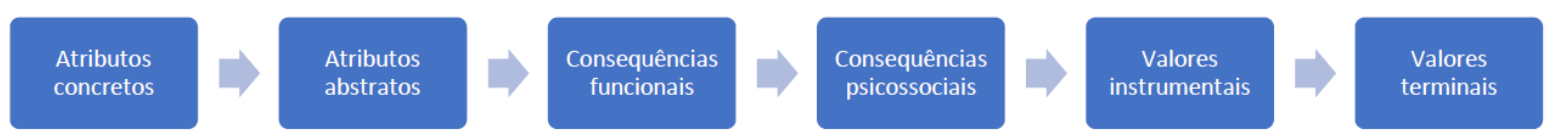

Fonte: Adaptado de (OLSON; PETER, 2008).

conduz ao estado da sabedoria. Valor terminal é relacionado a estados finais (felicidade, segurança e realização). Valores terminais são crenças duradouras, modos específicos de conduta, que, se aprovadas, levam a estados finais desejáveis, como realização Pessoal, conviver bem com as pessoas e sabedoria. A teoria meios-fins conecta esses três níveis de conhecimento do consumidor para formar uma cadeia hierárquica simples de associações, como demonstrado na Figura 1.

A teoria meios-fins afirma que os critérios de escolha mais importantes em uma decisão são as experiências antecipadas ou as consequências associadas às várias alternativas de escolha.

A teoria meios-fins é uma ferramenta poderosa que permite entender melhor como e porque as pessoas tomam as decisões em diversas situações. Ao oferecer informações detalhadas sobre o processo de tomada de decisão, a teoria meios-fins fornece indícios que possibilitam o desenvolvimento de melhores produtos e serviços.

\section{METODOLOGIA}

\subsection{Coleta de dados}

Para a coleta de dados, foram selecionados e entrevistados 22 participantes com idade igual ou superior a 60 anos. Esse tamanho da amostra atende ao requisito mínimo de tamanho de amostra recomendado por Reynolds e Olson (2001).

As entrevistas ocorreram entre abril de 2019 e dezembro de 2020 e a abordagem foi realizada por meio da técnica de entrevista semiestruturada chamada laddering.

Laddering baseia-se na identificação da cadeia Atributos-Consequências-Valores, usando os advérbios interrogativos "por quê?" para produzir construções mais gerais ou abstratas e "o quê" ou "como" para produzir os mais específicos (REYNOLDS; G, 1988). Assim a sequência das respostas dadas pelo entrevistado são classificadas em Atributos, Consequências e Valores.

As entrevistas foram gravadas em áudio e transcritas com a permissão dos participantes. Cada entrevista durou em média 45 minutos. Dados demográficos, como sexo, idade e escolaridade, foram inicialmente coletados por meio de um questionário. O questionário também abordou questões como a experiência do participante com jogos digitais e/ou de mesa e com que frequência eles jogam esses jogos. Em seguida, foi aplicado o Teste de Trilha para avaliar a capacidade cognitiva do participante (TOMBAUGH, 2004), seguido da leitura do Termo de 
Consentimento Livre e Esclarecido e a coleta da assinatura do participante.

A idade média dos participantes foi de 69 anos. Os participantes foram selecionados pela técnica de amostragem por conveniência.

Cada entrevista começou com o participante citando até três jogos digitais ou de mesa favoritos. Em seguida, o pesquisador apresentou uma pergunta geral para coletar quais recursos eram considerados importantes em um jogo, para aumentar a probabilidade de ser jogado e/ou apreciado. A partir dessa pergunta, as cadeias Atributos-Consequências-Valores foram construídas, uma para cada um dos recursos coletados.

O exemplo a seguir mostra parte de uma das entrevistas. O discurso do pesquisador é indicado por R, enquanto o discurso do entrevistado é indicado por E.

R: Com qual jogo ou com quais jogos, até três no máximo, você interage e gosta de jogar?

E: Damas.

$R:$ E que recurso esse jogo possui que faz você gostar dele?

E: Acho interessante.

$R$ : Por que este jogo é interessante para você?

E: Ele me diverte muito.

R: Por que divertir muito é importante para você?

E: Eu me sinto bem.

R: Por que se sentir bem é importante para você?

E: Se sentir bem nos faz felizes.

Alguns exemplos de jogos digitais citados foram Quebra-cabeça (digital), Paciência, BubbleShooter, Joias Preciosas e MightyParty, e alguns exemplos de jogos de mesa citados foram Poker, Palavras Cruzadas, Damas, Xadrez e Truco. Os participantes estavam livres para dizer o que quisessem, mas o entrevistador manteve algum nível de controle para explorar as importantes consequências e valores para os entrevistados em cada jogo e em cada atributo citado.

\subsection{Análise de dados}

Os dados coletados foram transcritos, organizados e codificados em categorias. As cadeias de meios-fim são construídas a partir das sequências de respostas dos participantes às perguntas "por quê?". Além disso, para análise dos dados, este estudo utilizou a Matriz de Implicação Estrutural, do inglês Structural Implication Matrix (SIM) e o Mapa Hierárquico de Valor, do inglês Hierarchical Value Map (HVM).

O SIM resume todos os relacionamentos em cadeia descritos entre Atributos, Consequências e Valores e representa as correlações quantificadas entre esses relacionamentos. 
Usando linhas e colunas para representar cada Atributo, Consequência e Valor, os números dentro da matriz representam as conexões entre os elementos representados pela linha e pela coluna. Em cada célula, existem dois números: o primeiro número representa os links diretos e o segundo, os links indiretos entre dois elementos das cadeias. Lin e Lin (2014) argumentam que "os números na matriz representam a frequência de cadeias entre os elementos; a frequência representa a força das correntes entre os elementos; quanto maior o número, mais forte a cadeia e vice-versa".

Por sua vez, HVM é um diagrama de rede em forma de árvore que é uma representação gráfica do mapa agregado de estruturas cognitivas (REYNOLDS; G, 1988). Correlações em cadeia do SIM são tomadas como base de referência para uma compilação de HVM (REYNOLDS; G, 1988).

Neste trabalho, a ferramenta LadderUX (ladderux.org) foi utilizada para armazenar os elementos de estudo, gerar o SIM e o HVM, possibilitando a análise de dados categorizados. LadderUX é uma ferramenta para ajudar na análise quantitativa de dados obtidos por meio de laddering.

Um pesquisador foi responsável pela codificação e categorização dos elementos. Cinco pesquisadores realizaram verificação de codificação e categorização. Para esse fim, foram realizadas várias reuniões entre os pesquisadores para discutir códigos e sua melhor categorização.

ATLAS.ti (atlasti.com) foi a ferramenta usada para categorizar os elementos coletados. ATLAS.ti é um ambiente de trabalho para a análise qualitativa de dados textuais, gráficos, de áudio e vídeo. Neste estudo, o processo de codificação e categorização resultou em 16 categorias de atributos, 12 categorias de consequências e 12 categorias de valores, totalizando 40 categorias, como pode ser visto no Quadro 1.

Para análise de confiabilidade, dois pesquisadores criaram independentemente as cadeias na ferramenta LadderUX. O LadderUX foi usado no processo de revisão para comparar os elementos liberados pelo pesquisador que codificou na opção Main Dataset com os dados liberados pelo pesquisador que revisou na opção Second coder da ferramenta.

Para verificar a confiabilidade das cadeias obtidas, foi utilizado o coeficiente Kappa de Cohen, que "é uma medida estatística de concordância entre avaliadores para itens qualitativos. Considera-se geralmente uma medida mais robusta do que o simples cálculo percentual de concordância, uma vez que leva em consideração a concordância que ocorre por acaso" (VIEIRA; KAYMAK; SOUSA, 2010). A ferramenta LadderUX também verifica e calcula automaticamente o coeficiente Kappa de Cohen.

O valor Kappa de Cohen gerado pela ferramenta LadderUX foi de 0,88. Russo, Donnelly e Reid (2006) argumentam que a pontuação acima de 0,80 indica alta confiabilidade. Landis e Koch (1977) argumentam que a estatística kappa 0,81 indica um nível de concordância com valor quase perfeito. 


\section{Quadro 1 - Atributos, Consequências e Valores}

\begin{tabular}{|c|c|c|c|c|c|c|c|}
\hline Elementos & Categoria & Item & & Frequência da citação & $\%$ & Frequência por participante & $\%$ \\
\hline \multirow{16}{*}{ Atributos } & \multirow{10}{*}{ Concreto } & A1 & Ter ranking & 1 & $1.12 \%$ & 1 & $4.54 \%$ \\
\hline & & A2 & Jogar com pessoas reais & 8 & $8.98 \%$ & 6 & $27.27 \%$ \\
\hline & & A3 & Ter um sistema de progresso & 12 & $13.48 \%$ & 6 & $27.27 \%$ \\
\hline & & A4 & Jogo de raciocínio & 34 & $38.20 \%$ & 15 & $68.18 \%$ \\
\hline & & A5 & Ter recompensa & 9 & $10.11 \%$ & 6 & $27.27 \%$ \\
\hline & & A6 & Animações & 2 & $2.24 \%$ & 2 & $9.09 \%$ \\
\hline & & A7 & Música & 1 & $1.12 \%$ & 1 & $4.54 \%$ \\
\hline & & A8 & Tempo de duração adequado & 1 & $1.12 \%$ & 1 & $4.54 \%$ \\
\hline & & A9 & Jogo sem imoralidade & 1 & $1.12 \%$ & 1 & $4.54 \%$ \\
\hline & & A10 & Exigir agilidade & 4 & $4.49 \%$ & 1 & $4.54 \%$ \\
\hline & \multirow{6}{*}{ Abstrato } & A11 & Recompensador & 4 & $4.49 \%$ & 3 & $13.63 \%$ \\
\hline & & A12 & Desafiar mente & 13 & $14.60 \%$ & 7 & $31.81 \%$ \\
\hline & & A13 & Jogo bonito & 4 & $4.49 \%$ & 2 & $9.09 \%$ \\
\hline & & A14 & Ter competição & 4 & $4.49 \%$ & 4 & $18.18 \%$ \\
\hline & & A15 & Jogo é divertido & 15 & $16.85 \%$ & 8 & $36.36 \%$ \\
\hline & & A16 & Instrutivo & 11 & $12.35 \%$ & 7 & $31.81 \%$ \\
\hline \multirow{12}{*}{ Consequências } & \multirow{4}{*}{ Funcionais } & $\mathrm{C} 1$ & Sentir que está melhorando & 18 & $20.22 \%$ & 8 & $36.36 \%$ \\
\hline & & $\mathrm{C} 2$ & Raciocinar para jogar & 10 & $11.23 \%$ & 5 & $22.72 \%$ \\
\hline & & $\mathrm{C} 3$ & Prazer em jogar & 7 & $7.86 \%$ & 5 & $22.72 \%$ \\
\hline & & $\mathrm{C} 4$ & Melhorar aspectos da vida real & 3 & $3.37 \%$ & 3 & $13.63 \%$ \\
\hline & \multirow{8}{*}{ Psicossociais } & $\mathrm{C} 5$ & Distração & 19 & $21.34 \%$ & 12 & $54.54 \%$ \\
\hline & & C6 & Ter saúde mental & 13 & $14.60 \%$ & 7 & $31.81 \%$ \\
\hline & & $\mathrm{C} 7$ & Estreitar laços & 13 & $14.60 \%$ & 8 & $36.36 \%$ \\
\hline & & $\mathrm{C} 8$ & Vencer desafios & 12 & $13.48 \%$ & 8 & $36.36 \%$ \\
\hline & & C9 & Sensação de bem-estar & 16 & $17.97 \%$ & 11 & $50.00 \%$ \\
\hline & & $\mathrm{C} 10$ & Raciocinar melhor & 16 & $17.97 \%$ & 12 & $54.54 \%$ \\
\hline & & $\mathrm{C} 11$ & Aprender & 10 & $11.23 \%$ & 6 & $27.27 \%$ \\
\hline & & C12 & Ficar tranquila & 3 & $3.37 \%$ & 3 & $13.63 \%$ \\
\hline \multirow{12}{*}{ Valores } & \multirow{6}{*}{ Instrumentais } & V1 & Sentir-se capaz & 29 & $32.58 \%$ & 12 & $54.54 \%$ \\
\hline & & $\mathrm{V} 2$ & Ter qualidade de vida & 14 & $15.73 \%$ & 9 & $40.90 \%$ \\
\hline & & V3 & Estar alegre & 5 & $5.61 \%$ & 4 & $18.18 \%$ \\
\hline & & V4 & Ter saude & 6 & $6.74 \%$ & 4 & $18.18 \%$ \\
\hline & & V5 & Ficar relaxada & 7 & $7.86 \%$ & 4 & $18.18 \%$ \\
\hline & & V6 & Interesse em aprender & 3 & $3.37 \%$ & 2 & $9.09 \%$ \\
\hline & \multirow{6}{*}{ Terminais } & V7 & Ter liberdade & 4 & $4.49 \%$ & 3 & $13.63 \%$ \\
\hline & & V8 & Ter paz & 5 & $5.61 \%$ & 5 & $22.72 \%$ \\
\hline & & V9 & Realização pessoal & 9 & $10.11 \%$ & 4 & $18.18 \%$ \\
\hline & & V10 & Conviver bem com as pessoas & 11 & $12.35 \%$ & 8 & $36.36 \%$ \\
\hline & & V11 & Autoestima & 6 & $6.74 \%$ & 5 & $22.72 \%$ \\
\hline & & V12 & Sabedoria & 3 & $3.37 \%$ & 3 & $13.63 \%$ \\
\hline
\end{tabular}

Fonte: Elaborado pelos Autores.

\section{RESULTADOS}

Neste estudo foram analisadas as cadeias principais que se destacaram a partir dos atributos com maior frequência. As seções a seguir contêm os esclarecimentos iniciais e os principais atributos, consequências, valores e suas relações. 


\subsection{Matriz de implicação estrutural}

Na matriz de implicação, todos os links foram obtidos usando um nível de corte. O nível de corte permite definir a filtragem de links usando sua frequência para incluí-los na HVM. O nível de corte especifica o limite para o número de links a serem incluídos na HVM.

A Matriz de Implicação Estrutural (SIM) obtida possui as seguintes características: 94 cadeias (uma média de 5,11 por participante) com 386 links diretos (uma média de 17,54 links por participante) e 671 links indiretos (uma média de 30,50 links por participante), totalizando 1057 ligações entre as 40 características descritas. Embora o SIM forneça um resumo de todas as cadeias e elementos, se todas as cadeias forem adicionadas à HVM, essa fica repleta de ligações, possivelmente ofuscando as cadeias que realmente importam para os respondentes. Para isso, foi necessário definir um nível de corte, tornando a HVM mais representativa. Trabalhos anteriores sugerem que um nível de corte que mantém um tamanho de amostra entre $50 \%$ e $60 \%$ pode representar as informações mais relevantes (REYNOLDS; OLSON, 2001). Assim, neste estudo, foi escolhido 2 como nível de corte.

\subsection{Principais atributos e suas relações}

Examinando a HVM gerada após a aplicação de um nível de corte 2, um dos atributos que provou ser os mais importantes para o público-alvo, com relação ao uso de jogos, é: Jogo de raciocínio. Esse atributo têm uma conexão clara com o valor terminal Realização pessoal. Nas próximas subseções, as principais cadeias geradas a partir desses atributos (Figura 2) são analisadas em detalhe.

\subsubsection{Atributos concretos}

Os participantes apontaram alguns atributos concretos que demonstram a importância para eles de um jogo de raciocínio. Entre os atributos reunidos como Jogo de raciocínio, destacam-se: Procurar palavras, O jogo tem armadilhas, Escolher as cartas, Agrupar cores, Lidar com números, Jogar cartas para formar palavras, Manipular aquelas peças. Alguns trechos das entrevistas exemplificam as opiniões dos participantes sobre o assunto:

"O jogo tem algumas armadilhas para tentar chamar sua atenção. Portanto, é preciso ter cuidado para ver o que o jogo está pedindo e o que está lá.”

(P14, feminino, 65 anos, $O$ jogo tem armadilhas)

“[...] o jogo te coloca sob pressão mental para usar as cartas que você tem na mão, porque você nem sempre pode conseguir outras cartas. Às vezes falta uma carta e você tem que jogar com o que tem na mão, usar as cartas que tem na mão. 


\section{Figura 2 - Principais atributos e suas cadeias}

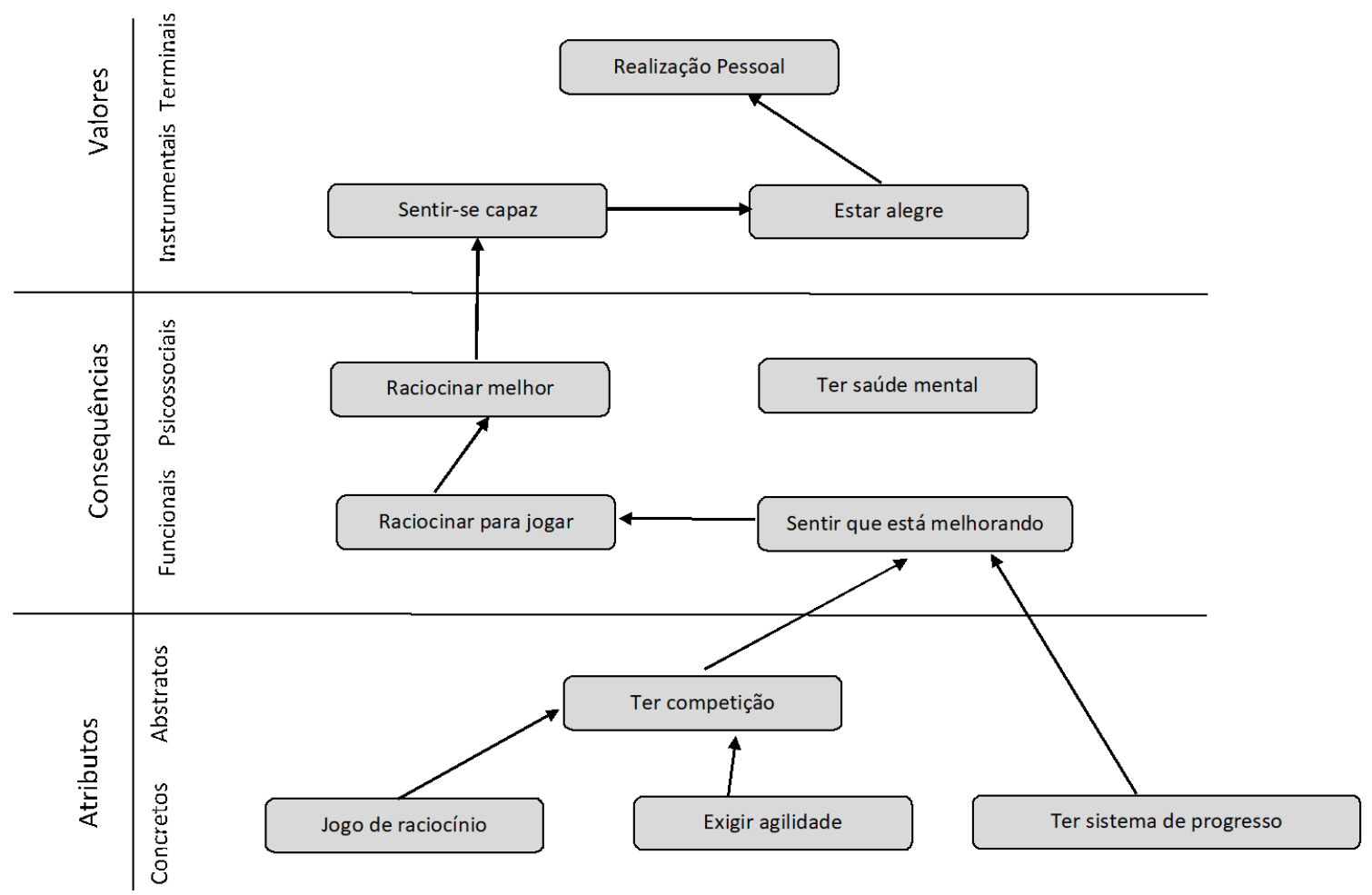

Fonte: Elaborada pelos Autores.

E enquanto você mexe com elas, de repente você se lembra de uma palavra que estava escondida em sua mente”.

(P17, feminino, 71 anos, Jogar cartas para formar palavras)

Quinze participantes apontaram a relevância de um Jogo de raciocínio. Atributos como Desafia os conhecimentos, Jogo obriga a pensar, Usar as cartas que tem na mão, Nunca uma mão é igual a outra, Ter que saber responder as questões, Combinação das cartas, Fazer as combinações corretas e Jogo de estratégia compõem a categoria Jogo de raciocínio e ocorreram em 34 cadeias.

"[...] e as damas eu acho muito interessante porque é um jogo de estratégia, você tem que prestar atenção no jogo do outro, você se pergunta onde você pode ir, então é interessante porque você vê que você foi bobo, que você não tinha pensado naquele jogo e quando você vê, já está perdido, e é legal; eu acho que é legal, esta mudança, ao mesmo tempo que você está ganhando se você não prestar atenção no outro jogador, você verá que você já perdeu, você tem que se concentrar, você tem que estar muito calmo para jogar".

(P02, feminino, 64 anos, Jogo de estratégia) 


\subsubsection{Atributos abstratos}

Todos os atributos concretos descritos na subseção anterior estão conectados ao atributo abstrato Desafiar a mente: sete links com Jogo de raciocínio e quatro links com Exigir Agilidade. Diversas características mencionadas possuem relação com a necessidade de um jogo desafiador da mente, fazendo com que esse atributo apareça para 68\% dos entrevistados. Dentre os elementos categorizados como Desafiar a mente pode-se citar: Astúcia, Estimula concentração, Estimula o raciocínio, Testar o cérebro, Exige atenção, Negociação, Lembrar palavras, Exige paciência, Desafiador, Prender a atenção, Exige concentração.

“[...] é um jogo que depende de muita astúcia para saber o que está acontecendo na mente de outros concorrentes, outros jogadores".

(P06, masculino, 71 anos, Astúcia)

"Olha, isso estimula minha concentração, então, o que eu tenho que fazer... se eu conseguir um quebra-cabeça de um animal ou de uma paisagem, tenho que olhar muito para o desenho. Ele sempre mostra um desenho primeiro e depois embaralha ele; depois está em sua mente o desenho que você vai começar a montar, por exemplo, um animal; você começa a montar pelo rosto, pelo corpo do animal, começa com uma parte para desenvolver o resto. Se é uma paisagem, por exemplo, se eu lembro que tem uma montanha ou vegetação, então eu marco um desenho e começo a montar. O importante é a concentração e eu conseguir formar esse desenho, então acho interessante você ter essa expectativa de que possa retratar isso na tela".

(P02, feminino, 64 anos, Estimula concentração)

“Às vezes ele mostra um movimento, mas ir para lá nem sempre é uma boa opção. Ele exige atenção".

(P14, feminino, 65 anos, Exige atenção)

\subsubsection{Consequências funcionais}

Em relação às consequências funcionais, duas características se destacaram como de maior importância para os participantes: Sentir que está melhorando no jogo e Raciocinar para jogar.

Cerca de $36 \%$ dos participantes mencionaram elementos em jogos que demonstram a importância de sentir que você está melhorando no jogo. Esses elementos ocorreram em 18 escadas diferentes e incluem: Subir de nível, Passar a fase mais rapidamente, Ganhar no jogo, Avançar no jogo, Aumentar a capacidade, Aumentar as possibilidades, Ganhar batalhas, Concluir o jogo, Dominar o jogo, Superar as dificuldades, Terminar o jogo, Evoluir no jogo, Chegar 
ao objetivo do jogo, Satisfação, Sensação de vitória, Recompensado com pontos, Não ser derrotado e Errar menos no jogo. Alguns trechos relacionados aos elementos citados são:

“[...] então, quando eu encontro uma pessoa que joga mais ou menos como eu, então estamos evoluindo juntos, uma vez ela ganha, uma vez eu ganho, porque se só eu ganhar, não tem graça, certo?"

(P11, masculino, 73 anos, Evoluir no jogo)

"Por causa da alegria de aproveitar aquele momento com outras pessoas, é muito bom. Isso me traz satisfação.”

(P20, feminino, 72 anos, Chegar ao objetivo do jogo)

"Como você se sente bem com algo que faz, você sempre quer fazê-lo, já que isso lhe dá uma sensação de vitória, de saber que você está crescendo."

(P20, feminino, 72 anos, Sensação de vitória)

Ver as possibilidades de jogada, Jogar com cuidado e Compor estratégia foram algumas características incluídas na categoria Raciocinar para jogar. Citadas por $45 \%$ dos entrevistados, demonstram a relevância do Raciocinar para jogar. Essas características ocorreram em 10 cadeias diferentes.

"Sim, porque isso te faz se comportar de forma extremamente discreta, para que outros jogadores não saibam quais são os possíveis movimentos ou cartas que você tem em sua mão".

(P06, masculino, 71 anos, Comportamento discreto)

"Isso porque estou estimulando meu sistema mental, auditivo e visual, estou praticando, certo?"

(P11, masculino, 73 anos, Estimulando)

\subsubsection{Consequências psicossociais}

Ter saúde mental é uma consequência psicossocial que apareceu em 13 cadeias diferentes. Essa consequência reúne diversas características relacionadas, dentre elas: Estimular a memória, Trabalhar com a mente, Melhorar a concentração, Ativar a memória, Abrir a mente, Melhorar a memória, Eliminar o bloqueio da mente, Ter uma boa memória, A mente fica mais limpa, Testar minha memória, A mente está boa e Ajudar na memória. Essas características foram citadas por $32 \%$ dos entrevistados. A seguir, frases que fazem referência a Ter saúde mental e características relacionadas:

"Porque eu preciso estimular minha memória. Estou ficando velho e preciso estimular minha memória."

(P01, feminino, 62 anos, Estimular a memória) 
"É porque isto é uma coisa diária, um lembrete para melhorar a memória e também uma satisfação de poder fazer algo. É algo que você não é obrigado a fazer, mas faz porque quer, está procurando e de alguma forma te dá prazer."

(P03, feminino, 62 anos, Melhorar a memória)

"É por isso que o jogo é importante, ele vai testar minha memória." (P07, feminino, 66 anos, Testar minha memória)

"Tenho medo que meu cérebro pare de reagir, ajudando meu cérebro a ficar ativo, meio que testo meu cérebro com o jogo."

(P07, feminino, 66 anos, Manter o cérebro ativo)

Dentre os entrevistados, 54\% citaram elementos relacionados a Raciocinar melhor, que inclui: Ter lucidez, Entender o que o jogo está pedindo, Abrir conexões mentais, Precisar raciocinar, Estimular o cérebro, Raciocinar melhor, Desenvolver raciocínio, Lidar melhor com situações do dia a dia, Exercitar a mente, Jogo obriga a pensar, Planejar previamente, Melhorar a atenção, Ter uma mente aguçada, Ilumina a mente e Estimular a memória. Esses elementos ocorreram em 16 cadeias diferentes.

“[...] É engraçado, né? Continuo pensando que estou aqui jogando este jogo que o menino encontrou para mim, mas dá uma boa sensação de que ainda temos uma certa lucidez de algo com mente aberta, para aprender coisas novas, para discutir com outras pessoas, com uma criança, certo? Com um neto, certo? Sobre um assunto, certo? Porque isso gera temas para falar, certo?"

(P10, feminino, 65 anos, Ter lucidez)

"Os pensamentos ficam mais rápidos, a concentração melhora."

(P01, feminino, 62 anos, Melhora a concentração)

"Ah, isso nos ajuda, certo? ajuda a abrir mais nossa mente, o fato de que você se concentra em algo, e ajuda a melhorar seu raciocínio."

(P03, feminino, 62 anos, Abrir a mente)

"Isso porque, neste caso, estou mudando para melhor, certo? Porque estou ficando mais atento."

(P10, feminino, 65 anos, Melhorar a atenção)

"É porque na idade que tenho, quando fico melhor, minha mente está funcionando bem, é claro, tenho uma mente aguçada, certo? Minha mente fica mais aguçada." (P14, feminino, 65 anos, Ter uma mente aguçada) 


\subsubsection{Valores instrumentais}

As características relacionadas a Sentir-se capaz foram citadas por 54\% dos participantes, ocorrendo em 29 cadeias diferentes. Algumas das características mencionadas, que foram agrupadas em Sentir-se capaz, são: Sentir-se útil, Desejo de vencer, Sentir-se capaz, Superar, Autonomia, Mostrar que não é inútil, Independência, Manter-se ativo, Incentivar a melhorar, Ter sempre novos desafios, Ter uma ocupação, Fazer direito em todas as situações, Alcançar metas, Prazer em realizar tarefas e Terminar tudo o que você começou.

"Porque o desejo de vencer é tão bom, certo? O desejo de vencer, de fazer certo. (P14, feminino, 65 anos, Desejo de vencer)

"Acho muito desagradável quando você começa algo e não termina. Dá uma sensação de vazio, de inutilidade. Esta característica é importante para mostrar que eu não sou inútil."

(P19, feminino, 62 anos, Mostrar que não é inútil)

"Acho que sempre terei algo para jogar, algo para fazer; cada vez um desafio diferente."

(P14, feminino, 65 anos, Ter sempre novos desafios)

"Acho que preenche nosso tempo, ocupa o tempo. Você tem uma ocupação." (P14, feminino, 65 anos, Ter uma ocupação)

"Porque tudo o que começamos temos que terminar, temos que completar; até mesmo um jogo."

(P19, feminino, 62 anos, Terminar tudo o que você começou)

"Eu não gosto de deixar algo meio feito. Eu gosto de terminar o que comecei."

(P12, feminino, 69 anos, Terminar tudo o que você começou)

Os entrevistados também demonstraram a relevância de Sentir-se bem para eles, que inclui os elementos Sentimento de contentamento, Sentir-se bem e Sentir-se vivo.

"Isso é ótimo! Hoje em dia você não precisa mais saber das coisas; isso o ativa, o faz sentir-se mais vivo."

(P02, feminino, 64 anos, Sentir-se vivo)

"Porque quando me afasto de coisas que não são nada agradáveis, eu me sinto melhor.

(P20, feminino, 72 anos, Sentir-se bem)

Por fim, os entrevistados ressaltaram elementos associados a Estar alegre, tais como Me faz feliz e Ter um momento de alegria.

"É uma das poucas coisas que eu acho que o homem tem. É a busca disso, de ter um momento de alegria e prazer, porque hoje em dia não é fácil ter isso."

(P06, masculino, 71 anos, Ter um momento de alegria) 


\section{DISCUSSÃO}

O jogo ser divertido foi apontado como algo importante tanto em jogos de mesa quanto em jogos digitais. Além disso, é interessante notar como outros atributos relevantes para o público idoso estão diretamente relacionados ao conceito de diversão apresentado, todos eles relacionados a processos cognitivos (Exigir agilidade, Jogo de raciocínio, Desafiar a mente) ou a satisfação pessoal (Recompensador, Ter um sistema de progresso, Ter desafio, Ter objetos colecionáveis). É importante destacar a diferença entre Jogo de raciocínio e Desafiar memória. Para os participantes, o primeiro se refere a jogos do estilo puzzle, como jogos de lógica, enquanto o segundo se refere a jogos que exigem memorização e concentração.

Para atender a esse interesse dos idosos, é importante respeitar teorias já existentes. Segundo a teoria do fluxo e a teoria da diversão (KOSTER, 2013), a diversão em jogos vem da capacidade do jogador de dominar os desafios que são colocados em seu caminho. Se o desafio for muito difícil para o jogador, ele se sentirá frustrado e desistirá. Por outro lado, se o desafio for fácil demais, ele se sentirá entediado e sem motivação para prosseguir no jogo, não se sentido recompensado ao prosseguir. A diversão ocorre na medida em que o jogador sente estar evoluindo no jogo, aprendendo algo e/ou dominando uma habilidade.

A partir dos resultados, foi possível identificar que os idosos podem ser atraídos por um jogo por causa de seus atributos de entretenimento, utilizando-o principalmente como hobby, diversão e relaxamento. No entanto as análises mostraram que os idosos estão interessados em jogar quando veem essa ação como uma opção, de baixo custo, para ajudá-los a manter sua saúde e melhorar sua qualidade de vida.

Outro fator identificado como importante é a necessidade de feedback sobre as ações que estão acontecendo. Elogiar um jogador para que ele saiba que está evoluindo no jogo e apresentar a ele o que está acontecendo, por exemplo, por meio de uma barra ou gráficos de progresso, contribui para proporcionar a ele maior controle sobre suas ações e, consequentemente, maior envolvimento.

O uso de elementos que favorecem a interação social também foi percebido, como valores de convivência entre as pessoas e obter bons relacionamentos. Alguns relataram esse recurso como um grande motivador, porque o fato de conhecer novas pessoas ou jogar com ou contra amigos os fazem se sentirem mais engajados e mais envolvidos na atividade. Nesse contexto, é possível destacar os jogos sociais que têm como principais atrações: a possibilidade de brincar com os outros em tempo assíncrono, publicar atividades nas redes sociais, sistema de recompensa (etapas de desbloqueio, por exemplo), a competição com outros jogadores e a possibilidade de melhorar o status social, especialmente quando o jogo divulga rankings. Jogos intergeracionais também podem se destacar nesse assunto, pois permitem maior interação entre avós e filhos ou netos.

Durante a análise dos dados, também foi possível perceber que a maioria dos participantes buscam jogos para poder auxiliar na manutenção de aspectos cognitivos, e procuram nos jogos uma maneira de lidar com atividades de lazer e diversão com benefícios à saúde, ajudando 


\section{Quadro 2 - Atributos citados apenas para jogos digitais}

\begin{tabular}{|l|c|}
\hline \multicolumn{1}{|c|}{ Atributo } & Num. pessoas \\
\hline Ranking (1) & 1 \\
\hline Ter recompensa (9) & 6 \\
\hline Animações (2) & 2 \\
\hline Musica (1) & 1 \\
\hline $\begin{array}{l}\text { Tempo de duração adequado } \\
(1)\end{array}$ & 1 \\
\hline Exigir agilidade (4) & 1 \\
\hline Recompensador (4) & 3 \\
\hline
\end{tabular}

Fonte: Elaborado pelos Autores.

\section{Quadro 3 - Atributos citados apenas para jogos de mesa}

\begin{tabular}{|l|c|}
\hline \multicolumn{1}{|c|}{ Atributo } & Num. pessoas \\
\hline Jogo sem imoralidade (1) & 1 \\
\hline jogar com pessoas reais (8) & 6 \\
\hline Instrutivo (11) & 7 \\
\hline
\end{tabular}

Fonte: Elaborado pelos Autores.

a melhorar seu bem-estar e a aumentar sua expectativa de vida.

Tomando como base a matriz de implicação estrutural e as cadeias geradas, foi possível levantar quais foram os atributos citados apenas para jogos digitais, os atributos citados apenas para jogos de mesa e, por fim, os atributos que foram citados para ambos os tipos de j ogos. Os Quadros 2, 3 e 4 apresentam essas informações, respectivamente, além do número de pessoas que citou cada atributo.

A maior parte dos atributos citados apenas para jogos digitais somente são possíveis para essa modalidade de jogos, por exemplo: Ranking, Animações e Música. Contudo, os atributos que só foram citados para jogos de mesa podem ser considerados no desenvolvimento de jogos digitais. Em particular, os atributos listados no Quadro 4 destacam-se pelo número de citações e por demonstrarem que são importantes, independente da modalidade do jogo.

\section{Quadro 4 - Atributos citados para jogos de mesa e digitais}

\begin{tabular}{|l|c|}
\hline \multicolumn{1}{|c|}{ Atributos (digital/mesa) } & Num. pessoas \\
\hline Ter um sistema de progresso (11/1) & 6 \\
\hline Ter competição (3/4) & 4 \\
\hline Jogo de raciocínio (22/12) & 15 \\
\hline Instrutivo (10/1) & 7 \\
\hline Desafiar a mente (5/8) & 7 \\
\hline Jogo bonito (3/1) & 4 \\
\hline Jogo é divertido (9/6) & 8 \\
\hline
\end{tabular}

Fonte: Elaborado pelos Autores. 
Figura 3 - Características de jogos para idosos
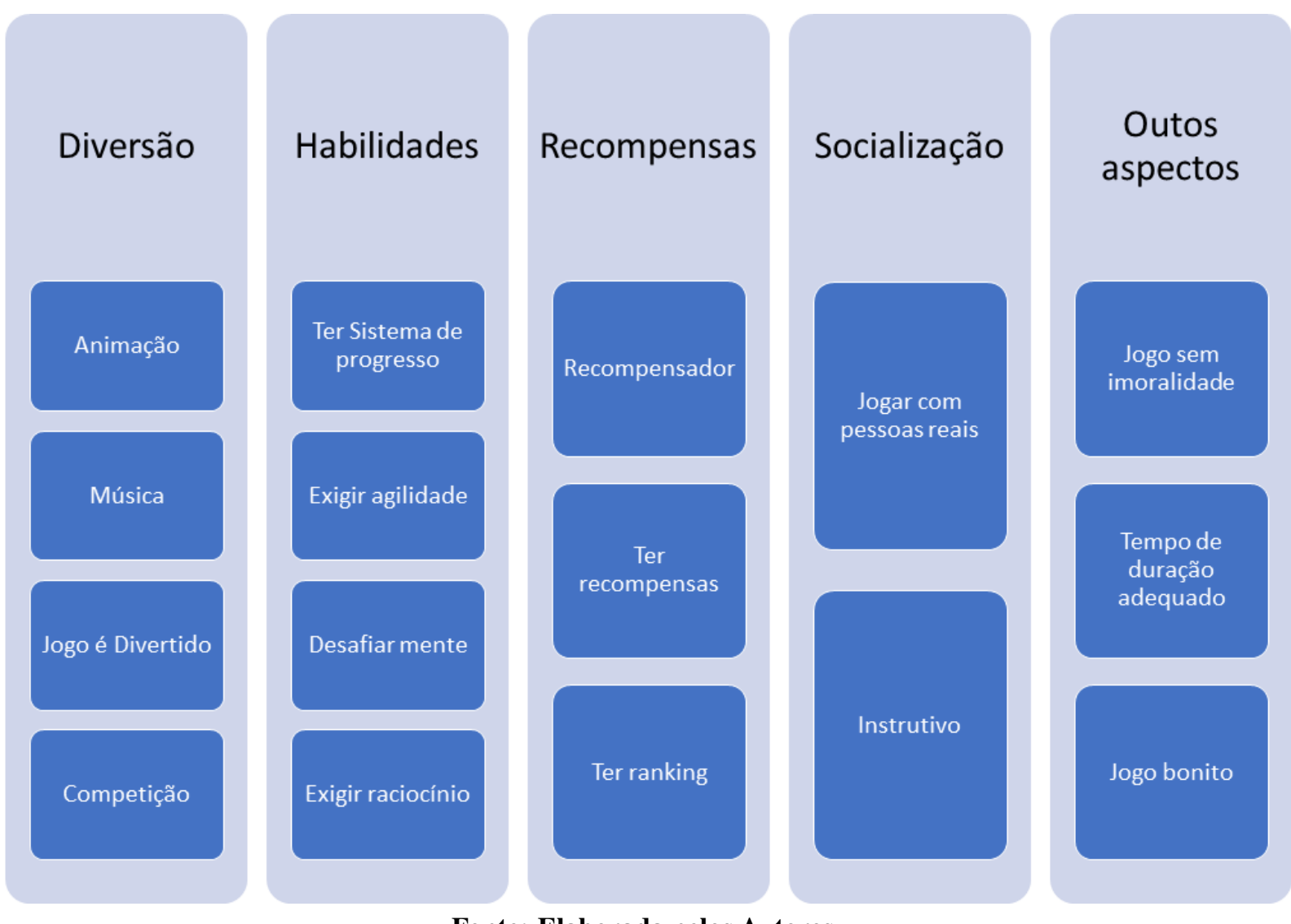

Fonte: Elaborada pelos Autores.

\section{CONCLUSÕES}

O objetivo deste trabalho foi apresentar os resultados de um estudo realizado com 22 idosos para saber suas preferências em relação a jogos e, a partir da análise dos dados coletados, gerar uma lista de atributos (ou características de jogos) relacionados a valores que são importante para os idosos em jogos. Os resultados refletem a experiência do usuário e podem ser usados para desenvolver jogos para o público-alvo estudado. A Figura 3 apresenta uma síntese dos resultados obtidos, organizados em cinco classes: diversão, habilidades, recompensas, socialização e outros aspectos. Cabe esclarecer que a classe Socialização inclui o atributo Instrutivo, porque alguns entrevistados indicaram que esse aspecto contribui para uma vida social mais ativa, por oferecerem mais assuntos para conversas.

É importante ainda lembrar que as consequências e valores identificados são aspectos a serem estudados por desenvolvedores de jogos para os idosos, pois outras estratégias de design podem ser pensadas para atender aos interesses do público-alvo deste trabalho.

De acordo com os resultados obtidos, este estudo indica uma preferência dos idosos pelo gênero de jogos de raciocínio, além de indicar que os jogos se apresentam como uma ferramenta que permite melhorar a qualidade de vida, a realização pessoal e a sensação de bemestar. Considerando a diversidade de características das pessoas com idade acima de 60 anos, seria interessante que trabalhos futuros buscassem consolidar os resultados obtidos por meio de 
estudos longitudinais e quantitativos, organizados por faixa etária e nível de escolaridade. 


\section{REFERÊNCIAS}

BANNON, L. Reimagining hci: Toward a more human-centered perspective. Interactions, ACM, New York, NY, USA, v. 18, n. 4, p. 50-57, jul. 2011. ISSN 1072-5520.

BERLIN, I. The Crooked Timber of Humanity: Chapters in the History of Ideas. Princeton, USA: Princeton University Press, 2013.

BOEREMA, S. T. et al. Value-based design for the elderly: An application in the field of mobility aids. Assistive Technology, Taylor Francis, v. 29, n. 2, p. 76-84, 2017.

BOTSCHEN, G. Using means-end structures for benefit segmentation. Interactions, European Journal of Marketing, v. 33, n. 4, p. 38-58, jan. 1999. ISSN 1072-5520.

FLANAGAN, M. Values at play in digital games. Cambridge, Massachusetts: The MIT Press, 2016. ISBN 978-0262529976.

GERLING, K.; SCHILD, J.; MASUCH, M. Exergame design for elderly users: The case study of silverbalance. In: Proceedings of the 7th International Conference on Advances in Computer Entertainment Technology. New York, NY, USA: ACM, 2010. p. 66-69.

GIBBINS, K.; WALKER, I. Multiple interpretations of the rokeach value survey. The Journal of Social Psychology, v. 133, p. 797-805, 121993.

GUTMAN, J. A means-end chain model based on consumer categorization processes. Journal of Marketing, v. 46, n. 2, p. 60-72, 1982.

IJSSELSTEIJN, W. et al. Digital game design for elderly users. In: Proceedings of the 2007 Conference on Future Play. New York, NY, USA: ACM, 2007. (Future Play '07), p. 17-22. ISBN 978-1-59593-943-2.

JONES, R. A.; SENSENIG, J.; ASHMORE, R. D. Systems of values and their multidimensional representations. Multivariate Behavioral Research, Informa UK Limited, v. 13, n. 3, p. 255270, jul 1978.

KOSTER, R. Theory of Fun for Game Design. Sebastopol, Califórnia, EUA: O'Reilly Media, 2013. ISBN 1449363210.

LANDIS, J. R.; KOCH, G. G. The measurement of observer agreement for categorical data. Biometrics, International Biometric Society, v. 33, n. 1, 1977.

LIN, H.-W.; LIN, Y. Digital educational game value hierarchy from a learners' perspective. Computers in Human Behavior, v. 30, p. 1 - 12, 2014. ISSN 0747-5632.

MACHADO, M. C. Uma proposta de heurísticas para avaliação de gameplay direcionada a adultos mais velhos. 2014. Dissertação (Mestrado) - Pontifícia Universidade Católica de Minas Gerais, Programa de Pós-Graduação em Informática, Belo Horizonte, 2014.

OLSON, J. C.; PETER, J. P. Consumer Behavior and Marketing Strategy. New York: McGraw-Hill, 2008. ISBN 9780071111775.

ONU. Mundo terá 2 bilhões de idosos em 2050. 2019. Disponível em <http://bit.ly/ 2E7SQ7N>. Acesso em: 13 abr. 2019. 
PEREIRA, R.; BARANAUSKAS, M. C. A value-oriented and culturally informed approach to the design of interactive systems. International Journal of Human-Computer Studies, v. 80, p. $66-82,2015$. ISSN 1071-5819.

REYNOLDS, T. J.; G, J. Laddering theory, methods, analysis and interpretation. Journal of Advertising Research, US: Advertising Research Foundation, v. 28, p. 11-31, 1988. ISSN 1740-1909 (Electronic); 0021-8499 (Print).

REYNOLDS, T. J.; OLSON, J. C. Understanding Consumer Decision Making. London: Routledge, 2001.

RICE, M. et al. Evaluating gesture-based games with older adults on a large screen display. In: ACM SIGGRAPH 2011 Game Papers. New York, NY, USA: ACM, 2011. (SIGGRAPH' 11), p. 3:1-3:8. ISBN 978-1-4503-0970-7.

ROKEACH, M. The nature of human values. New York: Free press, 1973.

RUSSO, K.; DONNELLY, M.; REID, A. J. Segregation-the perspectives of young patients and their parents. Journal of Cystic Fibrosis, v. 5, n. 2, p. 93 - 99, 2006. ISSN 1569-1993.

SCHWARTZ, S. H.; BILSKY, W. Toward a universal psychological structure of human values. Journal of Personality and Social Psychology, American Psychological Association (APA), v. 53, n. 3 , p. 550-562, 1987.

TOMBAUGH, T. N. Trail making test a and b: Normative data stratified by age and education. Archives of Clinical Neuropsychology, v. 19, n. 2, p. 203-214, 2004.

VIEIRA, S.; KAYMAK, U.; SOUSA, J. Cohen's kappa coefficient as a performance measure for feature selection. In: International Conference on Fuzzy Systems. New York: IEEE, 2010. p. $1-8$. 